\title{
WestVirginiaUniversity
}

THE RESEARCH REPOSITORY @ WVU

Graduate Theses, Dissertations, and Problem Reports

2019

\section{Effect of Metacarpal Gloves on Pinch and Grip Strength}

\author{
Aaron Anthony Fonner \\ aaf0010@mix.wvu.edu
}

Follow this and additional works at: https://researchrepository.wvu.edu/etd

Part of the Operations Research, Systems Engineering and Industrial Engineering Commons

\section{Recommended Citation}

Fonner, Aaron Anthony, "Effect of Metacarpal Gloves on Pinch and Grip Strength" (2019). Graduate Theses, Dissertations, and Problem Reports. 3816.

https://researchrepository.wvu.edu/etd/3816

This Thesis is protected by copyright and/or related rights. It has been brought to you by the The Research Repository @ WVU with permission from the rights-holder(s). You are free to use this Thesis in any way that is permitted by the copyright and related rights legislation that applies to your use. For other uses you must obtain permission from the rights-holder(s) directly, unless additional rights are indicated by a Creative Commons license in the record and/ or on the work itself. This Thesis has been accepted for inclusion in WVU Graduate Theses, Dissertations, and Problem Reports collection by an authorized administrator of The Research Repository @ WVU. For more information, please contact researchrepository@mail.wvu.edu. 


\title{
Effect of Metacarpal Gloves on Pinch and Grip Strength
}

\author{
Aaron A. Fonner \\ Thesis submitted to the Benjamin M. Statler College of \\ Engineering and Mineral Resources at West Virginia University \\ In partial fulfillment of the degree of
}

\section{Master of Science \\ In \\ Industrial Hygiene}

\author{
Ashish Nimbarte, Ph. D. Committee Chairperson \\ Xinjian He, Ph. D. \\ Eduardo M. Sosa, Ph. D
}

Department of Industrial and Management Systems Engineering

Morgantown, West Virginia

Spring 2019

Keywords: gloves, postures, pinch, grip

Copyright 2019 Aaron Fonner 


\section{Abstract \\ Effect of metacarpal gloves on pinch and grip Strength}

\section{Aaron Fonner}

Hand Injuries are common in industrial settings. In 2014 alone, there were 137,440 total cases of hand injuries in the United States that required days away from work. Hand injuries can be classified into six general categories: lacerations, fractures and dislocations, soft tissue injuries and amputations, infections, burns and high pressure injuries. Some of these injuries can be prevented with proper personal protective equipment. In recent times, metacarpal gloves are widely used to protect the workers against hand/metacarpal injuries in various industries including mining. The benefits of wearing metacarpal gloves for protection are unquestionable, but little is known about how these gloves can affect grip strength, pinch strength and the overall work performance. Therefore, the objective of this study was to determine if metacarpal gloves have an impact on user's gripping and pinching strengths. Five metacarpal gloves were evaluated using a sample size of 10 participants. Type of glove had a significant effect on the gripping strength. Use of glove, on an average, reduced the gripping strength by $20 \%$. Between the gloves, the gripping strength varied in the range of $3 \%$ to $10 \%$. The pinching strength was un-affected by the use of glove. 


\section{Acknowledgments}

I would sincerely like to thank Dr. Ashish Nimbarte for his guidance throughout my research. I'd also like to thank Dr. Xinjian "Kevin" He and Dr. Eduardo Sosa for their assistance, as well as all of the subjects that participated in this study.

Finally, I'd like to thank my family and friends for their support throughout my academic career. 


\section{Table of Contents}

Abstract..........................................................................

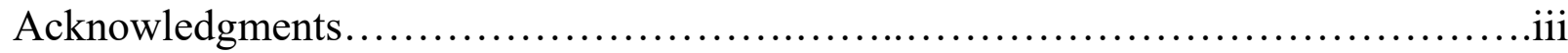

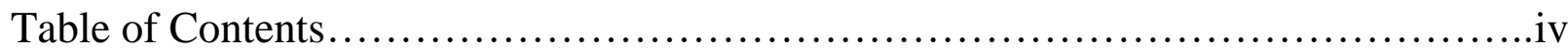

List of Figures...................................................................

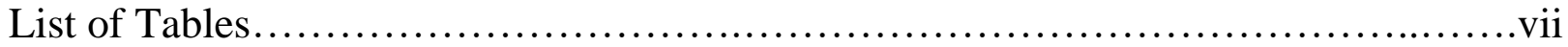

Chapter 1: Background and Introduction........................................

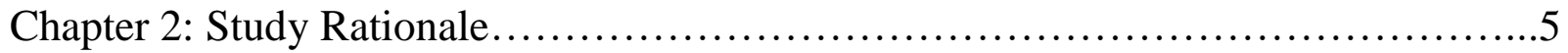

2.1 Problem Statement..............................................................

2.2 Objective and Hypotheses..................................................... 6

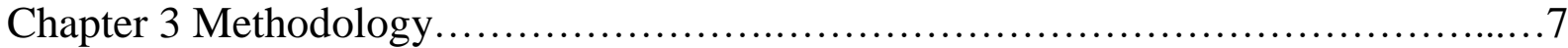

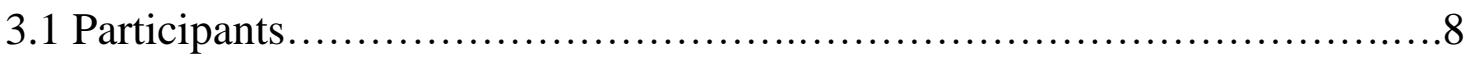

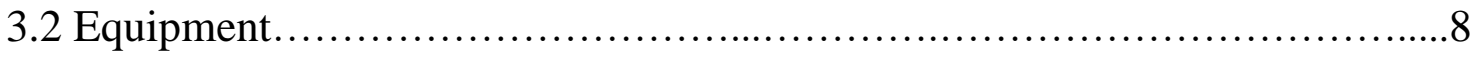

3.3 Metacarpal gloves................................................... 10

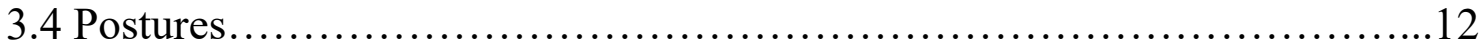

3.5 Experimental Design.................................................. 13

3.6 Statistical Analysis.................................................14

Chapter 4: Results......................................................... 15

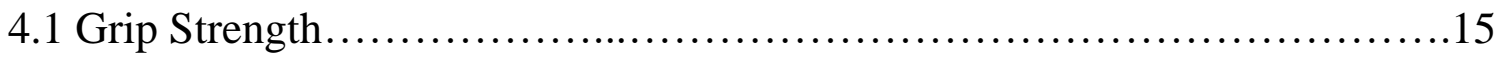

4.2 Pinch Strength...................................................... 18

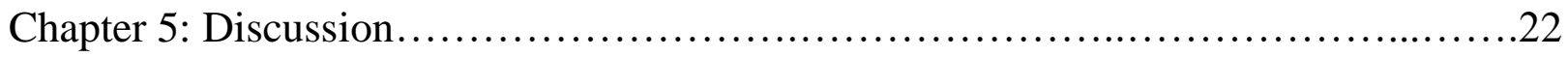

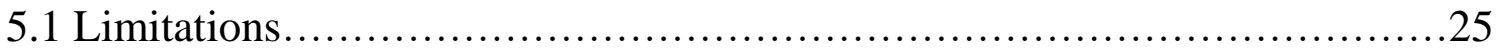

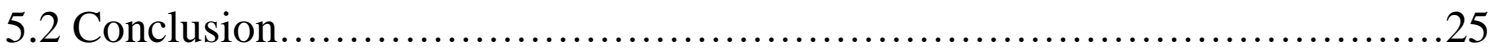

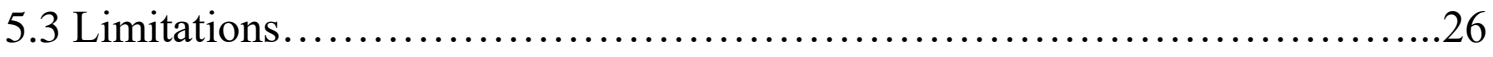

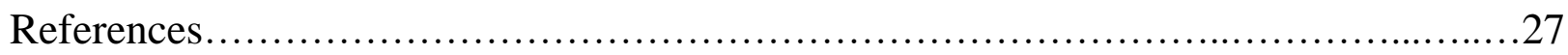

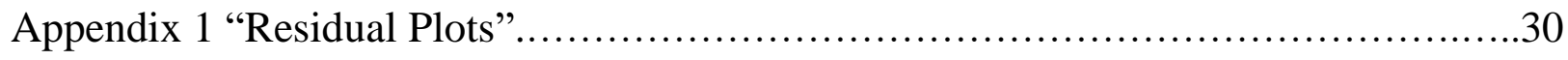

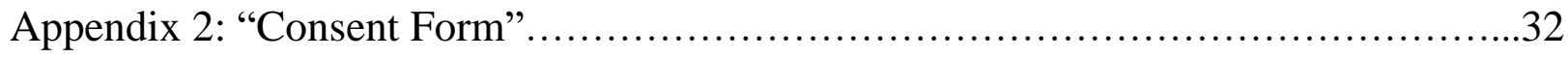




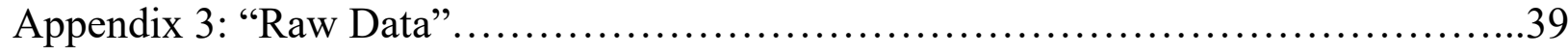




\section{List of Figures}

Figure 1: Key pinch grip.......................................................... 12

Figure 2: Power hand grip..............................................................

Figure 3: (A) Weight hung from pinch meter .................................. 14

Figure 3: (B) Reading of the weight on pinch meter............................. 14

Figure 4: (A) Weight hung from hand dynamometer................................15

Figure 4: (B) Reading of the weight on hand dynamometer.........................15

Figure 5: (1) Glove produced by West Chester................................... 16

Figure 5: (2) Glove produced by Wells Lamont..................................... 16

Figure 5: (3) Glove produced by Meta Miner....................................16

Figure 5: (4) Glove produced by Ringer Gloves.................................. 16

Figure 5: (5) Glove produced by Superior Glove...................................16

Figure 6: (A) Posture 1 using a Jamar hand dynamometer........................... 18

Figure 6: (B) Posture 1 using a Jamar pinch sensor..................................18

Figure 7: (A) Posture 2 using a Jamar hand dynamometer.......................... 19

Figure 7: (B) Posture 2 using a Jamar pinch sensor.................................19

Figure 8: Interaction plot for glove type and posture on pinch strength................27 


\section{List of Tables}

Table 1: Means and Standard Deviations (SDs) of Grip Strength for different glove conditions........................................................................ 21

Table 2: Means and Standard Deviations (SDs) of Grip Strength for different postures

Table 3: Result of Analysis of Variance (ANOVA) for the effect of glove type and

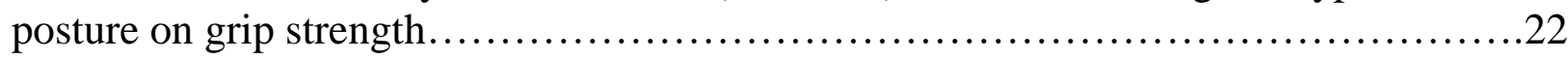

Table 4: (A) Main effect of glove type on grip strength.............................23

Table 4: (B) Main effect of posture on grip strength................................23

Table 3: (C) Results of Tukey HSD all-pairwise comparison test for glove type.........23

Table 4: (D) Results of Tukey HSD all-pairwise comparison test for posture.............23

Table 5: Means and Standard Deviations (SDs) of Pinch Strength for different glove

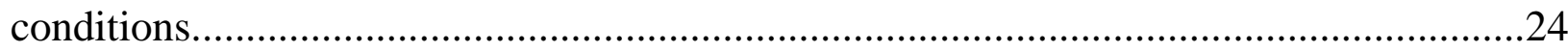

Table 6: Means and Standard Deviations (SDs) of pinch strength for different postures

Table 7: Result of Analysis of Variance (ANOVA) for the effect of glove type and

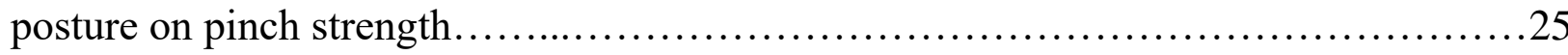

Table 8: (A) Main effect of glove type on pinch strength; (B) Main effect of posture on pinch strength; (C) Results of Tukey HSD all-pairwise comparison test for glove type; (D) Results of Tukey HSD all-pairwise comparison test for posture 


\section{Chapter 1: Background \& Introduction}

Hand injuries can be very taxing on employers and employees alike. In a lot of cases, hand injuries result in several days missed at work. In the United States, in 2016, the incidence rate was 315.9 per 10,000 full time workers and the number of cases that resulted in days away from work totaled 63,790 [2016 Survey Of Occupational Injuries and Illnesses Chart Data", 2018]. In 2012-2013 the Australian Workers' Compensation Statistics recorded 117,815 serious claims regarding the hands (Creagh 2018). In the Queensland mining industry, hand injuries are the second most common cause of lost work time. From 2007 to $2012 \sim 80 \%$ of all serious hand injuries fell under 4 categories: fractures (30\%), lacerations, cuts and other open wounds (25\%), crush injuries (15\%) and traumatic injuries (9\%) according to (Business Queensland, 2018).

Gloves can prevent many types of hand injuries such as: abrasions, punctures and breaks. However, gloves can inhibit movement of the hands which could cause a decrease in precision. Protective metacarpal gloves may also interfere with the ability to apply force on an object (Kovacs et al., 2002). The benefits of wearing gloves for protection are unquestionable, but we know very little about how they affect grip strength, pinch strength and the overall work performance. Metacarpal gloves in industrial settings like coal mining, are generally thicker work gloves constructed with leather or other synthetic materials and have additional protection on top of the metacarpal and finger zones. This thicker material used for glove construction causes the gloves to be stiff and rigid. "Knowledge of the effects of gloves on grip strength can help 
workers, managers, and safety professionals make decisions about glove selection and use in the workplace", (Wimer et al.,2010). This knowledge can also be useful to create a better design for future metacarpal gloves.

Workers in industrial settings such as coal mines are required to wear gloves for many reasons, the most important being safety. When determining the appropriate set of gloves for a task, an employer has a lot to consider when giving workers the proper set of gloves. Their gloves have to provide the worker with the right amount of protection, making sure the gloves aren't too thick to reduce tactile senses and making sure the gloves don't inhibit the worker's ability to apply the correct amount of force needed for a task. Some of the results of this study could be used to make that choice easier for employers.

Gripping, finger/thumb pinch are amongst most common tasks in gloves in industrial work places. There are a few studies that have analyzed the effect gloves can have on the users' force exertion ability, especially during gripping and pinching. Tsaousidis \& Freivalds, (1998) examined the effect of cotton gloves and double cotton glove which was wearing 2 pairs simultaneously on maximum force and the rate of force in pinch. The researchers found that the influence from the gloves decreased pinch force development by $30 \%$ to $70 \%$. They also discovered that there was a significant deterioration in grip force $(15 \%-20 \%)$. In a study by Rock et al, (2001) the authors found an $8 \%$ average decrease in pinch force while wearing leather gloves compared to no gloves in 45 healthy male and female volunteers. In that same study, there was an 
average $23 \%$ decrease in grip strength with a leather glove compared to the no glove tests.

In a study conducted by the University of Nebraska, the effect of two types of work gloves, deer hide and leather from cow hide, on the human performance capabilities was examined. The hypothesis was that the grip force would be impaired and so would other human capabilities. The researchers found that there was a reduction in maximum static grip force. The grip force decrement for the deer hide glove was $\sim 11 \%$ and the leather glove caused a 10\% decrease in grip force (Bishu et al., 1987).

Hallbeck \&McMullin, (1993) studied the effect of 5 different types of work gloves: cotton, knit, reinforced knit, combination of cotton and knit, and combination of cotton and reinforced knit on peak pinch force. They found that one average for all the gloves combined that there was a $4 \%$ decrease in pinching force from wearing the work gloves.

In a study that was interested in maximum pinch and grip forces, the authors had subjects wear military grade leather work gloves to complete tasks. The participants' mean power grip strength decreased by $28 \%$ and the mean power pinch strength decreased by $13 \%$ when glove condition was compared to an ungloved condition (Torrens, G.E. and Newman, A., 2000).

In an all-female study by Sung (2014), the effect of protective glovebox gloves on hand performance was examined. The gloves were fabricated from butyl, CSM/hypalon and with neoprene materials and three thicknesses: single, double and triple thickness. 
Hand performance actually increased with the thin single glove but decreased with the other two thicknesses. 


\section{Chapter 2: Study Rationale}

Personal protective equipment is mandatory by law. Nearly every industrial task involves use of one's hands so it is essential to keep them protected. In coal mines and steel mills, workers are required to wear gloves with extra protection over top of the metacarpals and fingers. The gloves provide ample protection, but they may compromise the ability to apply force while gripping and pinching. The unquestioned need for hand safety and the unknown performance compromise warrants further investigation into a relationship between the amount of protection provided and the hand performance.

\subsection{Problem Statement}

Safety should be the number one priority of any company. Grip strength and pinch strength are important in any industrial job that requires working with your hands. Coal miners are an excellent example of this. Every day, miners have to perform tasks that will be directly affected by pinch or grip strength like using chainsaws and drilling strategically placed bolts and plates into the roof to assure stability (Carrel 2018). During such industrial activities, bulky metacarpal gloves can ensure workers' safety but may hinder their ability to apply grip and pinch force, which may lower their overall performance. Very little is known about how metacarpal gloves can affect grip strength, pinch strength and the overall work performance. 


\subsection{Objective and Hypotheses}

The objective of this study was to determine how metacarpal gloves affect workers' hand performance while gripping and pinching compared to working bare handed. To reach the objective of this study, a set of experiments were designed and conducted on 5 types of metacarpal gloves typically used in the mining industry. Metacarpal gloves are very thick and work well for protecting against lacerations, burns and abrasions but they may compromise the ability to apply gripping and pinching force. The following hypotheses were tested in this study:

Null hypothesis 1: Grip force of participants will not be affected by the use of metacarpal gloves

Alternative hypothesis 1: Grip force of participants will decrease with the use of metacarpal gloves

Null hypothesis 2: Pinch force of participants will not be affected by the use of metacarpal gloves

Alternative hypothesis 2: Pinch force of participants will decrease with the use of metacarpal gloves 


\section{Chapter 3: Methodology}

A laboratory-based study was conducted to determine exactly how much a metacarpal glove can affect workers' hand performance. Maximum key pinch (Figure 1) and power hand grip (Figure 2) strengths were measured.

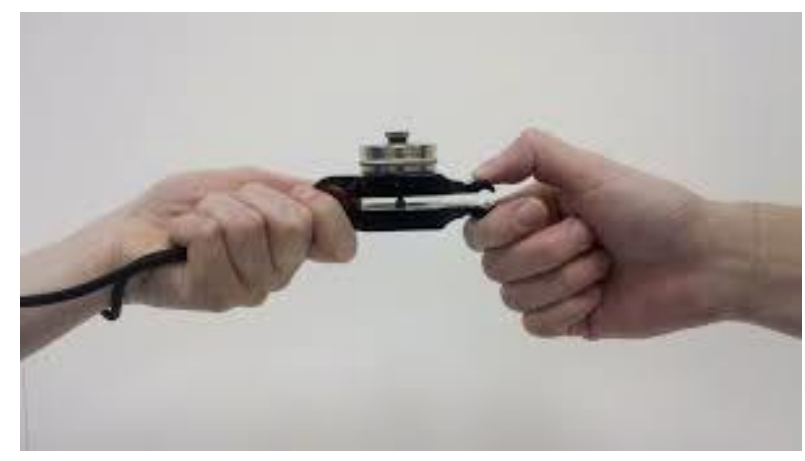

Figure 1: Key pinch grip using a Jamar pinch grip sensor.

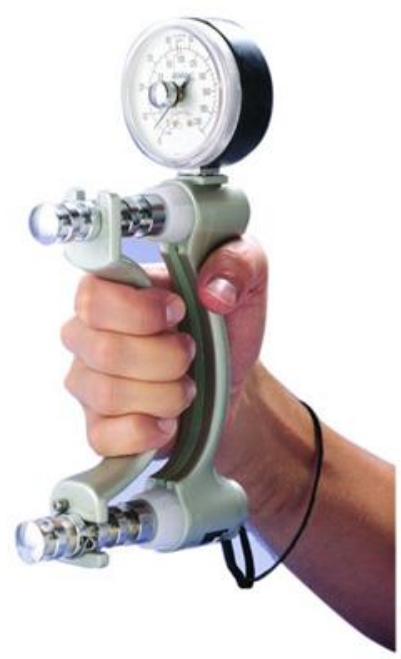

Figure 2: Power hand grip using Jamar hand dynamometer. 


\subsection{Participants}

A total of 10 college-aged males (24-26) were recruited for the research. The subjects had a mean height of 71.4 inches with a standard deviation of 2.6 inches. The mean age of the subjects was 24.9 years old with a standard deviation of 0.5 years. The mean weight of the subjects was 184.5 pounds with a standard deviation of 14.9 pounds. There were 9 right handed subjects and 1 left handed subject. Participants had to sign a Only Minimal Risk Consent Information Form (without HIPAA), which can be found in the Appendix 2: Consent Form. The primary inclusion criteria for this research required that all participants be free from any neurological symptoms, previous cardiac problems or any musculoskeletal disorders that would affect grip/pinch strength.

\subsection{Equipment}

A Jamar pinch meter and Jamar hydraulic hand dynamometer (JLW Instruments., Chicago IL) were used to measure the maximum strengths. Before and after each participant, 10 pounds of weight was hung from each device to ensure that the calibration was still correct as shown in (Figure 3) respectively. 


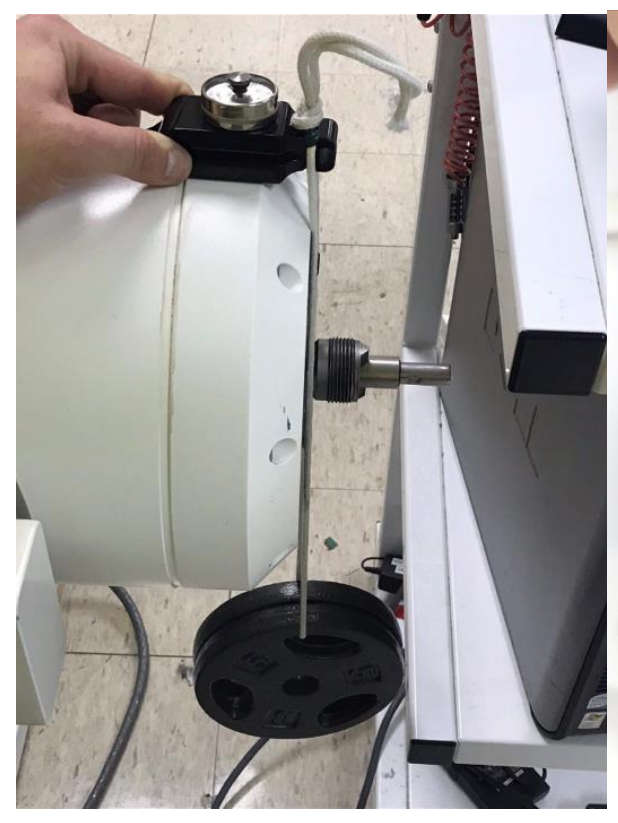

(A)

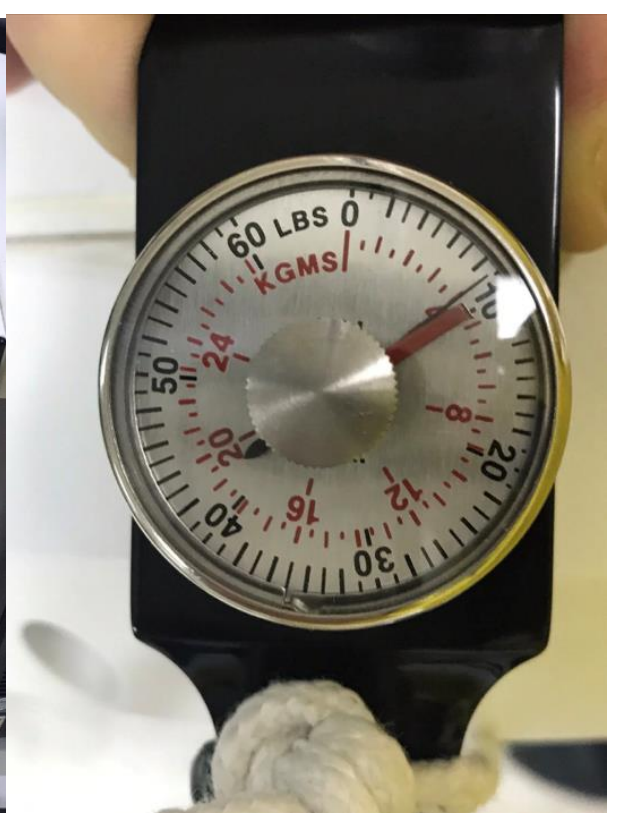

(B)

Figure 3: (A) Known weight of 10 pounds hung from the pinch meter; (B) The reading from the weight hung from the meter. (10 pounds).

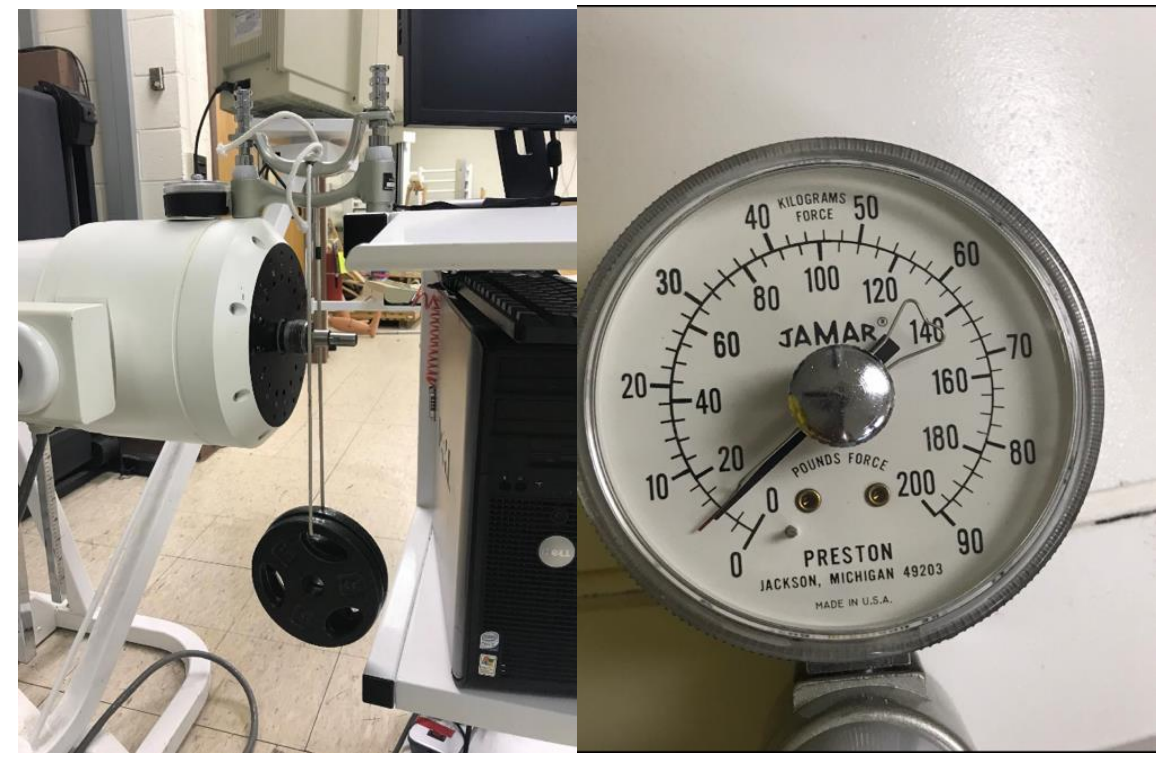

(A)

(B)

Figure 4: (A) A known weight of 10 pounds hung from the hand dynamometer; (B) The reading from the weight hung from the meter (10 pounds). 


\subsection{Metacarpal gloves}

Five different metacarpal gloves were tested in this study. In (Figure 5), glove 1 is a glove produced by West Chester Protective Gear. It is a split cow hide leather work glove with an elastic wrist band. Glove 2 is produced by Wells Lamont. It is the High-Vis Linebacker model. It has a synthetic leather palm with anti-slip finger patches for gripping. Glove 3 is produced by Meta Miner. These gloves are widely used in many mines located across the country. The palm is made of thermo plastic rubber (TPR) and has a padded hand and knuckle strap on the top. Glove 4 is produced by Ringers gloves. They are a high-visibility glove that have cut and puncture resistant materials on the dorsal side of the glove. Glove 5 is produced by Superior glove. This glove is made of goat skin leather and has impact protection from added gel padding on the dorsal side of the glove. 


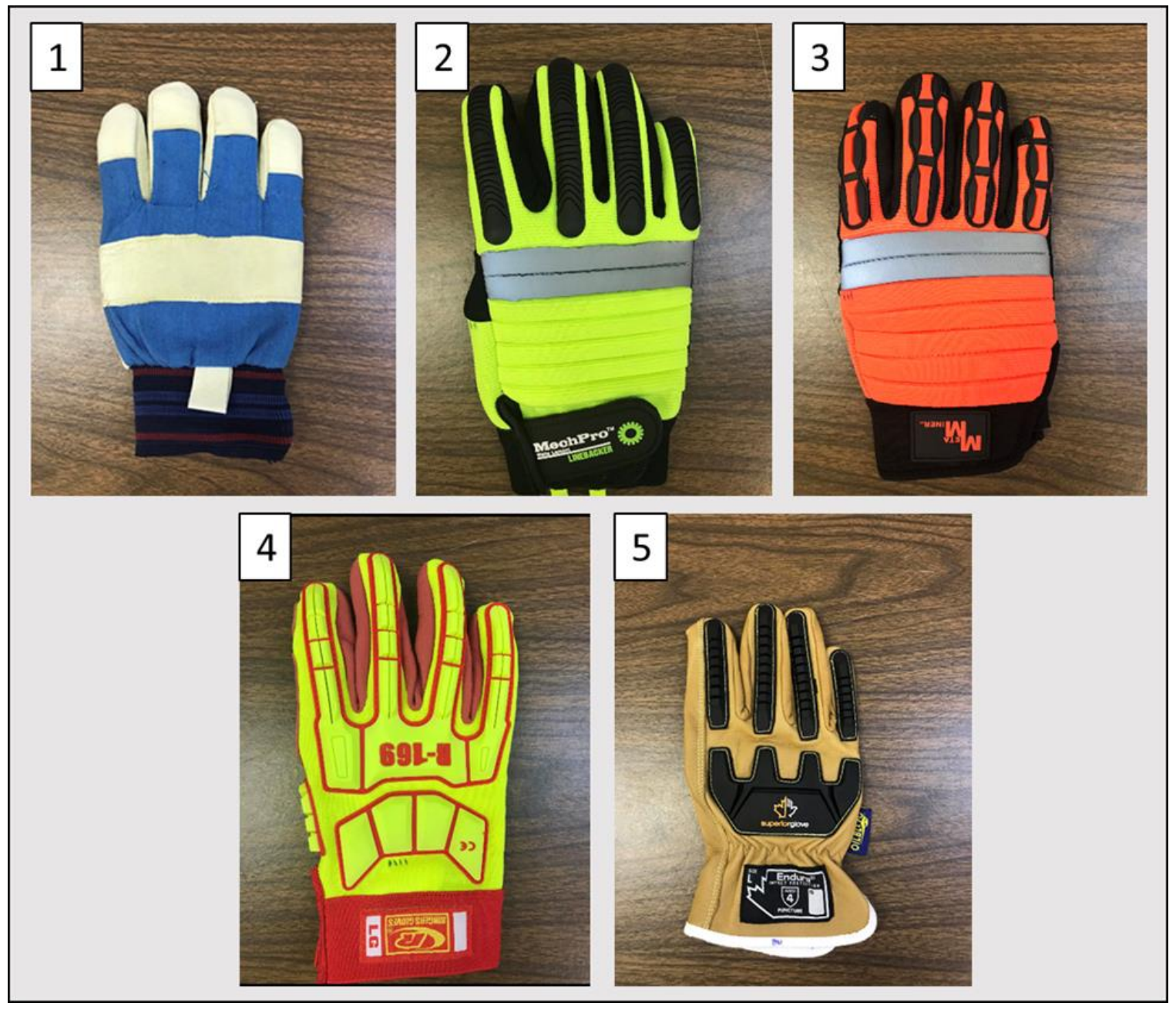

Figure 5: Five gloves tested in this study: (1) Glove produced by West Chester Protective Gear; (2) Glove produced by Wells Lamont; (3) Glove produced by Meta Miner; (4) Glove produced by Ringers Gloves; (5) Glove produced by Superior Glove. 


\subsection{Postures}

The gripping and pinching strengths were measured using 2 different postures. The first posture is standing, with the shoulder adducted and neutrally rotated and elbow in full extension (elbow at 90 degrees) as shown in (Figure 6). The second posture is standing as well and the arm was in full abduction with the bicep muscle close to the participant's ear and as close to 150 degrees as possible, as shown in (Figure 7). Subjects were asked to look at the ceiling where they were simulating overhead work. An angle of 150 degrees was chosen so that the participant was not uncomfortable looking straight up during the duration of the experiment.

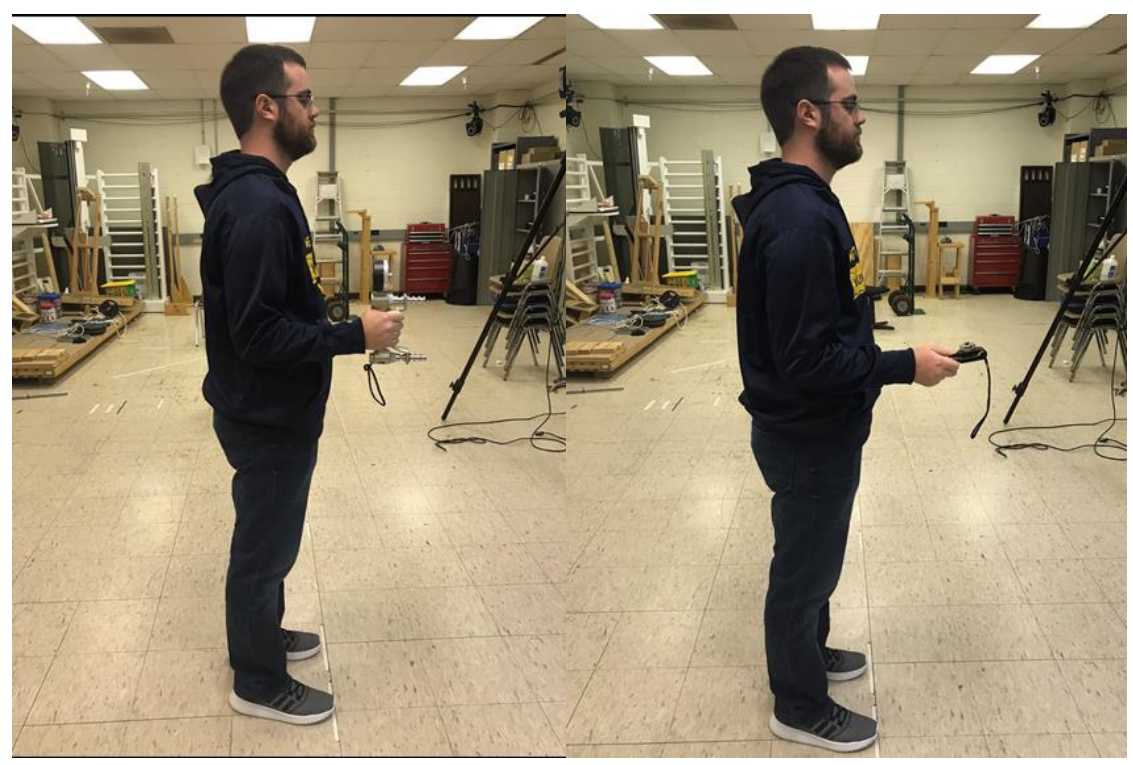

(A)

(B)

Figure 6: (A) Posture 1 using a Jamar hand dynamometer; (B) Posture 1 using a Jamar pinch sensor. 


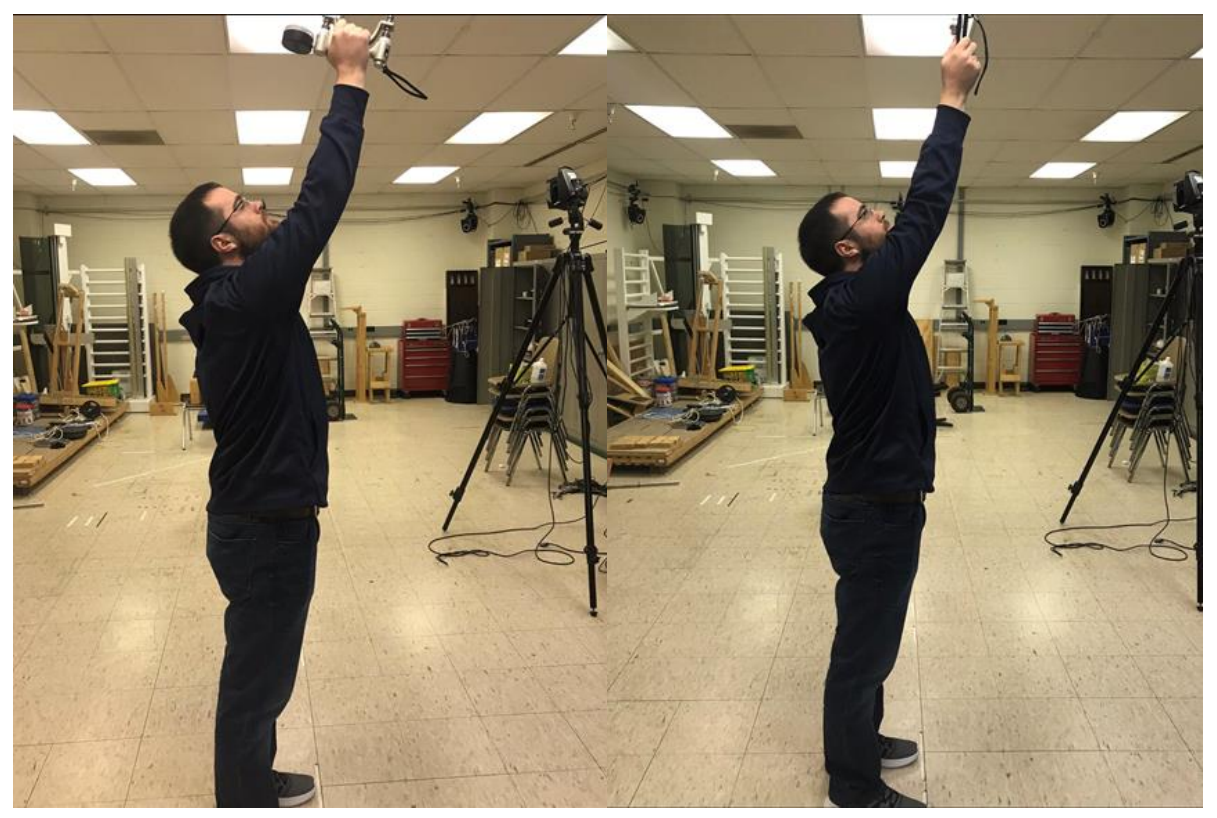

(A)

(B)

Figure 7: (A) Posture 2 using a Jamar hand dynamometer; (B) Posture 2 using a Jamar pinch sensor.

\subsection{Experimental design}

Each participant performed 72 experimental trials, compromised of: 2 types of force exertions (pinch and grip), 2 postures, 6 glove conditions and 3 repetitions. Each maximum force exertion trial involved applying the force slowly and steadily without a jerking motion, until maximum force is reached. Verbal ques were used to ensure slow and steady exertions by counting the following cadence (1,2 Maximum 4, maintain, 6 and relax), for a seven second count every trial. For each subject and each trial, they were 
encouraged to exert maximum strength through verbal reinforcement. Three trials of maximum strength measurements were collected. In the cases where variability was $>10 \%$ between trails, a 4 th trial was performed and the average of the highest 3 values was considered to be the representative pinch/gripping strength of the participant. The duration of the study for each participant was approximately three hours long. This long duration was due to a 2 minute long rest period in between each trial. Posture, grip/pinch and glove type were randomly selected using an Excel spreadsheet.

\subsection{Statistical analysis}

A two-factor general linear ANOVA was performed to evaluate the effect of posture and glove type on the grip and pinch strengths. Posture was treated as a fixed factor at two levels, 150 degrees overhead and 90 degrees to the side. Glove type was treated as a fixed factor at six levels, no glove, glove 1, glove 2, glove 3, glove 4 and glove 5. The participant was treated as a random factor. Significance level was set to 5\%, $(\mathrm{P}=.05)$. The significant main and/or interaction effects were further evaluated by conducting the comparisons between means using Tukey's HSD all-pairwise comparison test. The equality of variance test using a multiple comparison test showed that the assumption of an equal variance condition was valid in (Appendix 1). Furthermore, the adequacy of the linear model was confirmed by normal probability plots of the residuals between the actual and fitted value. Minitab 18 software (Minitab Inc., Pennsylvania, USA) was used to perform the statistical analysis. 


\section{Chapter 4: Results}

\subsection{Grip Strength}

Descriptive statistics for Grip Strength are shown in Tables 1 and 2. In general, the mean Grip Strength in pounds was higher for the no glove condition (106.78 pounds) compared to the with glove conditions ranging from ( 83.95 pounds- 92.65 pounds) for the different glove conditions. Among the five gloves, the mean grip strength was the highest for glove type 4 ( 92.65 pounds) and the lowest for glove type 1 (83.95 pounds). As summarized in (Table 1), mean grip strength for posture 2 was found to be higher than posture 1 .

Table 1: Means and Standard Deviations (SDs) of Grip Strength for different glove conditions.

\begin{tabular}{|llrr|}
\hline Variable & $\begin{array}{l}\text { Glove } \\
\text { type }\end{array}$ & Mean (Lbs) & SD (Lbs) \\
\hline Grip Strength & 0 & 106.78 & 16.37 \\
& 1 & 83.95 & 12.32 \\
& 2 & 90.03 & 16.46 \\
& 3 & 88.77 & 16.21 \\
& 4 & 92.65 & 15.67 \\
& 5 & 90.08 & 14.12 \\
\hline
\end{tabular}


Table 2: Means and Standard Deviations (SDs) of Grip Strength for different postures.

\begin{tabular}{|llrr|}
\hline Variable & Posture & Mean (Lbs) & SD (Lbs) \\
\hline Grip Strength & 1 & 89.63 & 15.56 \\
& 2 & 94.46 & 17.55 \\
\hline
\end{tabular}

Table 3: Result of Analysis of Variance (ANOVA) for the effect of glove type and posture on grip strength.

\begin{tabular}{|lrrrrr|}
\hline Source & DF & Adj SS & Adj MS & F-Value & P-Value \\
\hline Glove type & 5 & 18095 & 3618.92 & 67.23 & 0.000 \\
Posture & 1 & 2100 & 2100.08 & 39.02 & 0.000 \\
Participant number & 9 & 61701 & 6855.65 & 127.36 & 0.000 \\
Glove type*Posture & 5 & 446 & 89.23 & 1.66 & 0.144 \\
Error & 339 & 18248 & 53.83 & & \\
Lack-of-Fit & 99 & 15798 & 159.57 & 15.63 & 0.000 \\
Pure Error & 240 & 2450 & 10.21 & & \\
Total & 359 & 100589 & & & \\
\hline
\end{tabular}

The main effect of glove type on the grip strength was statistically significant (Table 1). In (Figure $8 \mathrm{~A}$ ), it can be seen that the highest mean grip strength was for the no glove condition. The results of the Tukey HSD all-pairwise comparison test showed that mean grip strength without a glove is different from the means with a glove (Figure 8 C). Among the five gloves, mean grip strength for glove 4 is different from glove 3 . Mean grip strength for glove 1 is different from the other four gloves. Results of the Tukey HSD all-pairwise comparison test showed that mean grip strength for posture 1 was different from posture 2. The interaction effect of glove type and posture on the grip strength was statistically not significant (Figure 10). 
Results of ANOVA (Table 3), and Tukey HSD all-pairwise comparison test conclude that the null hypothesis 1 is rejected and alternative hypothesis 1 is accepted, meaning that glove use and type of glove had an effect on participants' grip strength.

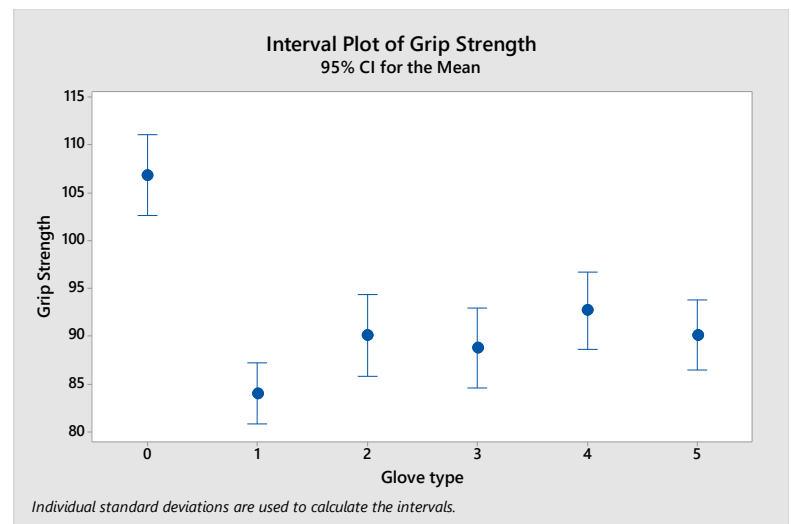

(A)

\begin{tabular}{|lrrrrrr|}
\hline $\begin{array}{l}\text { Glove } \\
\text { type }\end{array}$ & $\mathrm{N}$ & Mean (Lbs) & & Grouping \\
\hline 0 & 60 & 106.78 & $\mathrm{~A}$ & & \\
4 & 60 & 92.65 & & $\mathrm{~B}$ & & \\
5 & 60 & 90.08 & $\mathrm{~B}$ & $\mathrm{C}$ & \\
2 & 60 & 90.03 & $\mathrm{~B}$ & $\mathrm{C}$ & \\
3 & 60 & 88.77 & & $\mathrm{C}$ & \\
1 & 60 & 83.95 & & & $\mathrm{D}$ \\
\hline
\end{tabular}

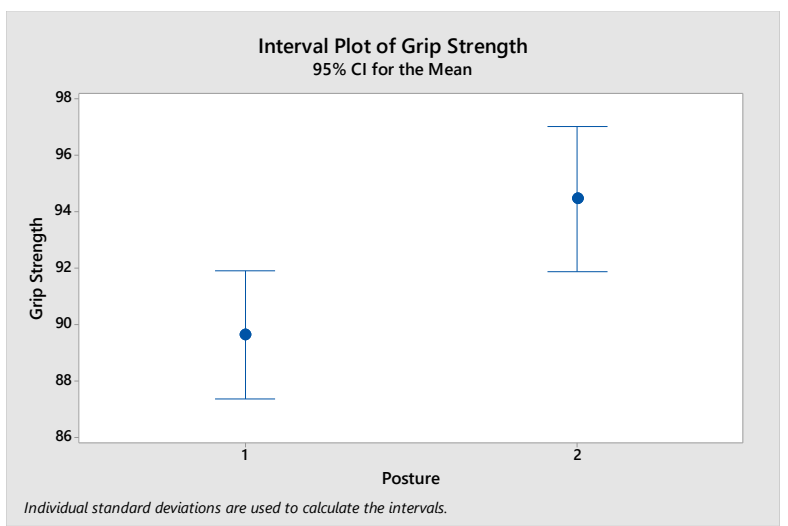

(B)

\begin{tabular}{|lrrr|}
\hline Posture & N & Mean (Lbs) & Grouping \\
\hline 2 & 180 & 94.46 & A \\
1 & 180 & 89.63 & B \\
\hline
\end{tabular}

(D)

Figure 8: Main effect of glove type (A) and posture (B) on grip strength. Results of Tukey HSD all-pairwise comparison test for glove type (C) and posture (D); means that do not share a letter are significantly different. 


\subsection{Pinch Strength}

Descriptive statistics for Pinch Strength are shown in Table 4 and Table 5. In general, the mean pinch strength was slightly higher under the glove conditions compared to no glove condition. Among the five gloves, mean pinch strength was the highest for glove type 2 and the lowest for the bare hand condition. Mean pinch strength for posture 1 was found to be higher than posture 2 .

Table 4: Means and Standard Deviations (SDs) of Pinch Strength for different glove conditions.

\begin{tabular}{|llrr|}
\hline Variable & $\begin{array}{l}\text { Glove } \\
\text { type }\end{array}$ & Mean (Lbs) & StDev (Lbs) \\
\hline Pinch Strength & 0 & 21.4 & 2.1 \\
& 1 & 22.2 & 1.8 \\
& 2 & 22.5 & 2.4 \\
& 3 & 22.3 & 2.2 \\
& 4 & 22.3 & 2.3 \\
& 5 & 22.3 & 2.2 \\
& & & \\
\hline
\end{tabular}

Table 5: Means and Standard Deviations (SDs) of Pinch Strength for different postures.

\begin{tabular}{|cccc|}
\hline Variable & Posture & Mean (Lbs) & SD(Lbs) \\
\hline Pinch Strength & 1 & 22.4 & 2.3 \\
& 2 & 22.0 & 2.1 \\
& & & \\
\hline
\end{tabular}


Table 6: Result of Analysis of Variance (ANOVA) for the effect of glove type and posture on pinch strength.

\begin{tabular}{|cccccc|}
\hline Source & DF & Adj SS & Adj MS & F-Value & P-Value \\
\hline Glove type & 5 & 41.01 & 8.203 & 6.39 & 0.000 \\
Posture & 1 & 14.60 & 14.601 & 11.38 & 0.001 \\
Participant number & 9 & 1195.92 & 132.880 & 103.58 & 0.000 \\
Glove type*Posture & 5 & 55.30 & 11.061 & 8.62 & 0.000 \\
Error & 339 & 434.91 & 1.283 & & \\
Lack-of-Fit & 99 & 304.91 & 3.080 & 5.69 & 0.000 \\
Pure Error & 240 & 130.00 & 0.542 & & \\
Total & 359 & 1741.74 & & & \\
\hline
\end{tabular}

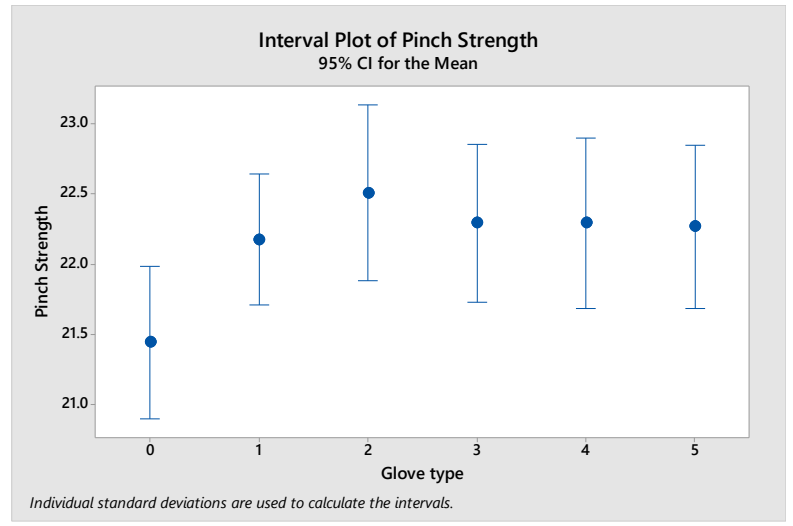

(A)

\begin{tabular}{|cccll|}
\hline $\begin{array}{c}\text { Glove } \\
\text { type }\end{array}$ & N & Mean (Lbs) & Grouping \\
\hline 2 & 60 & 22.5 & $\mathrm{~A}$ & \\
3 & 60 & 22.3 & $\mathrm{~A}$ & \\
4 & 60 & 22.3 & $\mathrm{~A}$ & \\
5 & 60 & 22.3 & $\mathrm{~A}$ & \\
1 & 60 & 22.2 & $\mathrm{~A}$ & \\
0 & 60 & 21.4 & & B \\
\hline
\end{tabular}

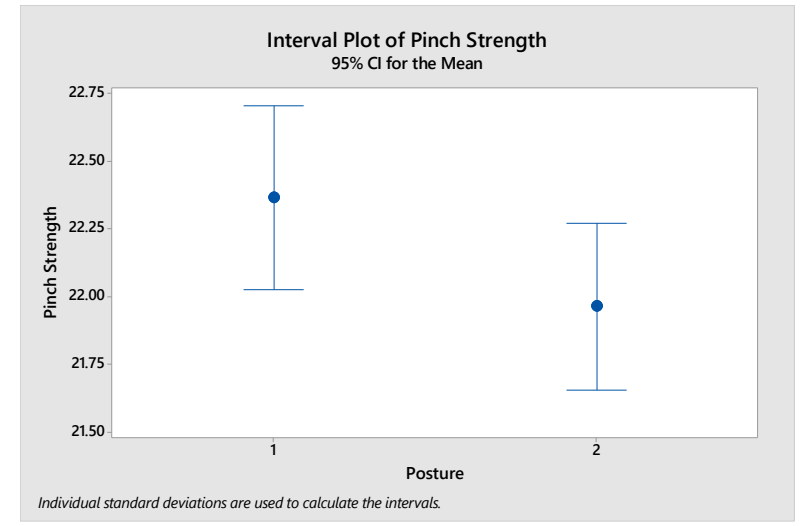

(B)

\begin{tabular}{|ccccr|}
\hline Posture & N & Mean (Lbs) & Grouping \\
\hline 1 & 180 & 22.4 & A r & \\
2 & 180 & 22.0 & & B \\
\hline
\end{tabular}


(C)

(D)

Figure 9:: Main effect of glove type (A) and posture (B) on pinch strength. Results of Tukey HSD all-pairwise comparison test for glove type (C) and posture (D); means that do not share a letter are significantly different.

The main effect of glove type on pinch strength was statistically significant (Table 6). However, the difference in strength was in the range of a few pounds of force. A similar observation can be made for the effect of posture on the pinch strength and interaction effect of glove type and posture on pinch strength.

ANOVA (Table 6), and Tukey HSD all-pairwise comparison test show that glove type and posture and interaction were significant for pinch strength. All glove types performed the same, and were better than the no glove condition. Null hypothesis 2 is rejected and alternative hypothesis 2 is accepted, meaning that glove use had an effect on pinch strength, however the difference in the strength was minimal and not meaningful from ergonomics injury point of view. 


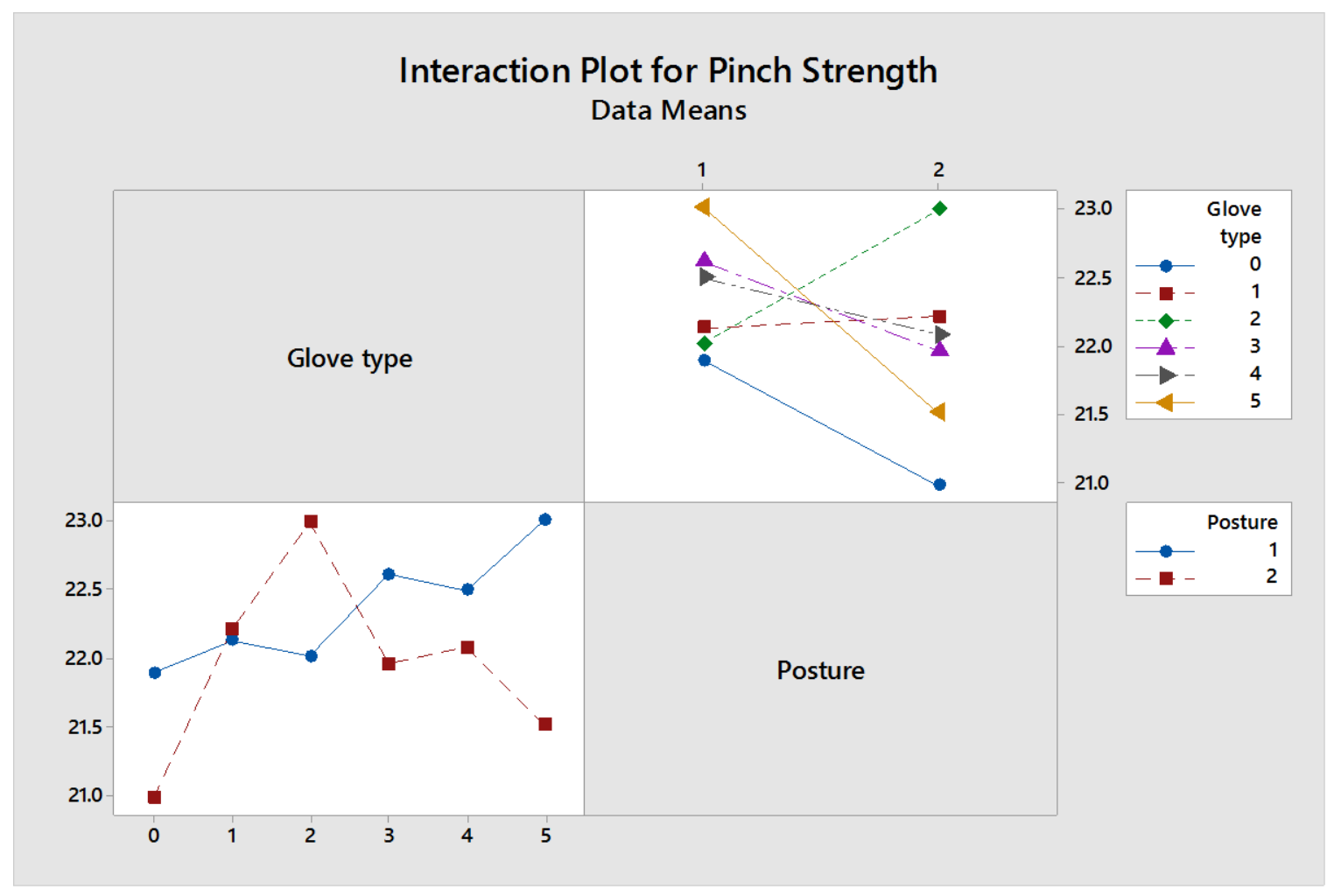

Figure 10: Interaction plot for glove type*posture on pinch strength.

On the $\mathrm{Y}$ axis in both graphs is force in pounds. Looking at the graph on the left it is seen that the ungloved condition has the lowest mean pinch strength of 21 pounds. Glove 1 had a mean pinch strength of 22.5 pounds. Glove 2 had a mean pinch strength of 23.0 pounds. Glove 3 had a mean pinch strength of 22.0 pounds. Glove 4 had a mean pinch strength of 22.0 pounds and glove 5 recorded a mean pinch strength of 21.5 pounds 


\section{Chapter 5: Discussion}

The mean peak grip strength observed in this study under no glove condition was 107 pounds and is very similar to values reported by Dodds et al., (2014), where they found that the male subjects' mean peak grip strength was 112.2 pounds. The mean pinch strength observed in this study under no glove condition was 21.4 pounds and is also comparable to a study by Dodds et al., (2014), where they found that the male subjects' mean peak pinch strength was 18 pounds. Unexpectedly, the pinch force was lowest when participants were not wearing gloves in (Table 4). It is possible that this was due in part to the added padding to the fingers that the gloves provided. The pinch meter is made of steel and becomes very uncomfortable to use after a few trials.

Researchers debate whether protective metacarpal gloves inhibit a worker's ability to perform pinching and gripping tasks while working. The study found that metacarpal gloves do negatively impact the ability to produce force when performing a gripping task, and is speculated that this is because of the thickness of the glove and the limited space in the hand dynamometer. Metacarpal gloves positively impacted the ability to produce force while performing a pinching task. There is a difference of 14-22 pounds between the no glove and glove conditions. Metacarpal gloves can have a negative impact on a worker's ability to produce griping force but, there isn't enough of an impact to disregard wearing gloves. A forceful pinch can be uncomfortable. Gloves may help a worker produce more pinching force because it provides comfort during an otherwise 
uncomfortable task. It was determined that these gloves decrease applied grip force, but it is unknown that if this decrease in force actually decreases performance. Future studies should quantify possible differences in ability to complete job-specific tasks between gloved and ungloved workers. If these future studies determine there really is no effect, then the obvious decision should be to choose the most protective gloves because it won't impact worker productivity.

In a study conducted by (Ramadan, 2017), they used a Jamar hand dynamometer and a similar design. A no glove condition and 5 different gloves, none of which were metacarpal gloves. The results are very comparable to this study. For their no glove condition, the mean grip strength was 100.0 pounds. For their glove 1, the mean grip strength was 76.0 pounds. Glove 2 showed a mean of 73.6 pounds. Glove 3 had a mean of 71.5 pounds. Glove 4 had a mean grip force of 88.7 pounds. Finally, glove 5 had a mean of 66.2 pounds. They concluded in their study that glove use generally reduced grip strength applied to the Jamar hand dynamometer and that total glove thickness is a main factor that influences grip strength.

In another study by Sung,(2014), it was found that gloves have no significant effect on key pinch strength compared to bare hand. In a previous study by [Dianat et al.(2012)], is it stated that a thicker glove decreases tactile perception and manual dexterity but adds more comfort. This extra comfort allows more pressure to be put on the finger tips during forceful exertions. This is reflected by the results of the current 
study because there is only a 1 pound difference between the different glove types and the no glove condition.

In the study there were higher force exertions in posture 2 for pinch and grip, (overhead posture). According to Parvatikar \& Mukkannavar, (2009), this overhead position allows the proximal muscles to stretch beyond their normal length which would increase their ability to exert force. Also contributing to posture 2 having higher strength, there is more muscle recruitment according to Thigpen et al.,(2010).

When comparing the gloves, the thinner gloves produced higher strength values compared to thicker gloves. The no glove condition was the highest for strength values. Glove (1) produced the lowest strength value ( 83.95 pounds) and it is because the glove is constructed out of thick cotton and leather, making it the thickest glove that was tested. The other gloves are made out of leather and lighter synthetic materials which makes them lighter and more flexible.

For pinching strength wearing any of the tested gloves produced higher strength values compared to the no glove condition. Glove (2) produced the highest strength value (22.5 pounds). As mentioned before, the difference in strength values among different glove types was minimal. The pinch sensor is an uncomfortable device to use continuously, that's why there are slightly higher strength values for all the different glove conditions compared to the no glove condition. The type of material i.e., cotton and leather, or a leather and synthetic material seem to have little effect on the pinch strength. 


\subsection{Limitations}

There are a few limitations in this study, with the most obvious being that the sample size is so small. Increasing the number of participants from 10 to perhaps 20 or 25 subjects would allow for more variability and could show more significant results. Another limitation would be the devices themselves. Though these devices are standard when measuring grip and pinch forces, it is possible that they are not ideal for industrial testing due to the limited amount of space to grip the devices for testing. The space given on the devices can be constricting or limited when using a bulky metacarpal glove. There was no randomization factor for this study and there is always a possibility of human error when reading force devices. For future studies, it would be very beneficial to use all electronic force devices if possible. Another possible limitation is that subjects become anxious and fatigued during the 3-3.5 hour long testing.

\subsection{Conclusions}

The study shows that during gripping tasks a no glove condition can generate more force than when wearing a glove, but working in an industrial setting without a glove isn't practiced. So, even though maximum force max may not be attained while wearing metacarpal gloves, it is always a good idea to keep gloves on to provide protection. It was also found that wearing gloves has a positive impact on the ability to produce force while pinching compared to a no glove condition. This is credited to the added comfortability 
that a glove provides while performing a pinching task. The overhead posture produced a higher force while gripping and this is caused by the positioning of the arm and the recruitment and lengthening of the proximal muscles used while performing the task.

\subsection{Implications}

Not many hand tools require $\sim 106$ pounds of gripping strength to operate so, each glove that I tested would be a good choice for workers performing gripping tasks. For pinching tasks, 20-23 pounds of pinch strength would be adequate for most tasks that would have to be performed. From this study, we can tell which gloves outperform others, but all of these glove would be a good choice for PPE. 


\section{References}

1. 1910.138 - Hand Protection. | Occupational Safety and Health Administration. (2018). Retrieved from https://www.osha.gov/lawsregs/regulations/standardnumber/1910/1910.138

2. Bishu, R., Batra, S., Cochran, D., \& Riley, M. (1987). Glove Effect on Strength: An Investigation of Glove Attributes. Proceedings Of The Human Factors Society Annual Meeting, 31(8), 901-905. doi: $10.1177 / 154193128703100812$

3. Creagh, B. (2018). Halting mining hand injuries and fatigue - Australian Mining. Retrieved from https://www.australianmining.com.au/oil-gas/haltingmining-hand-injuries-and-fatigue/

4. Carrel, F. (2018). Detailed description Underground production and development miners (NOC 8231) - LMI. Retrieved from http://imt.emploiquebec.gouv.qc.ca/mtg/inter/noncache/contenu/asp/mtg122_d escrprofession_01.asp?lang=ANGL\&pro=8231\&aprof $=8231$

5. Dodds, R., Syddall, H., Cooper, R., Benzeval, M., Deary, I., \& Dennison, E. et al. (2014). Grip Strength across the Life Course: Normative Data from Twelve British Studies. Plos ONE, 9(12), e113637. doi: 10.1371/journal.pone.0113637

6. Hallbeck, M. S., \& McMullin, D. L. (1991). Effect of gloves, wrist position, and age on peak three-jaw chuck pinch force. A pilot study. In Proceedings of 
the Human Factors Society (Vol. 1, pp. 753-757). Publ by Human Factors Soc Inc.

7. Kovacs, K., Splittstoesser, R., Maronitis, A., \& Marras, W. (2002). Grip Force and Muscle Activity Differences Due to Glove Type. AIHA Journal, 63(3), 269-274. doi: 10.1080/15428110208984713

8. Parvatikar, \& Mukkannavar. (2009). Comparative Study of Grip Strength in Different Positions of Shoulder and Elbow with Wrist in Neutral and Extension Positions. Journal Of Exercise Science \& Physiotherapy 5(2), 67-75. Retrieved from http://medind.nic.in/jau/t09/i2/jaut09i2p67.pdf

9. Preventing serious hand injuries | Business Queensland. (2018). Retrieved from . https://www.dnrme.qld.gov.au/business/mining/safety-and-health/alerts-andbulletins/mines-safety/preventing-serious-hand-injuries

10. Ramadan MZ. The Effects of Industrial Protective Gloves and Hand Skin Temperatures on Hand Grip Strength and Discomfort Rating. Int J Environ Res Public Health. 2017;14(12):1506. Published 2017 Dec 4. doi:10.3390/ijerph14121506

11. Rock, K., Mikat, R., \& Foster, C. (2001). The effects of gloves on grip strength and three-point pinch. Journal Of Hand Therapy, 14(4), 286-290. doi: $10.1016 / \mathrm{s} 0894-1130(01) 80007-7$

12. Sung, P. (2014). Effects of glovebox gloves on grip and key pinch strength and contact forces for simulated manual operations with three commonly used hand tools. Ergonomics, 57(10), 1512-1525. doi: 10.1080/00140139.2014.933888 
13. Torrens, G.E. and Newman, A., 2000. The evaluation of gloved and ungloved hands. In: P.T. McCabe, M.A. Hanson, and S.A. Robertson, eds. Contemporary ergonomics. London: Taylor \& Francis, 301-305.

14. Tsaousidis, N., \& Freivalds, A. (1998). Effects of gloves on maximum force and the rate of force development in pinch, wrist flexion and grip. International Journal Of Industrial Ergonomics, 21(5), 353-360. doi: 10.1016/s01698141(96)00086-8

15. Wimer, B., McDowell, T., Xu, X., Welcome, D., Warren, C., \& Dong, R. (2010). Effects of gloves on the total grip strength applied to cylindrical handles. International Journal Of Industrial Ergonomics, 40(5), 574-583. doi: 10.1016/j.ergon.2010.05.004 


\section{Appendix 1: Residual Plots}

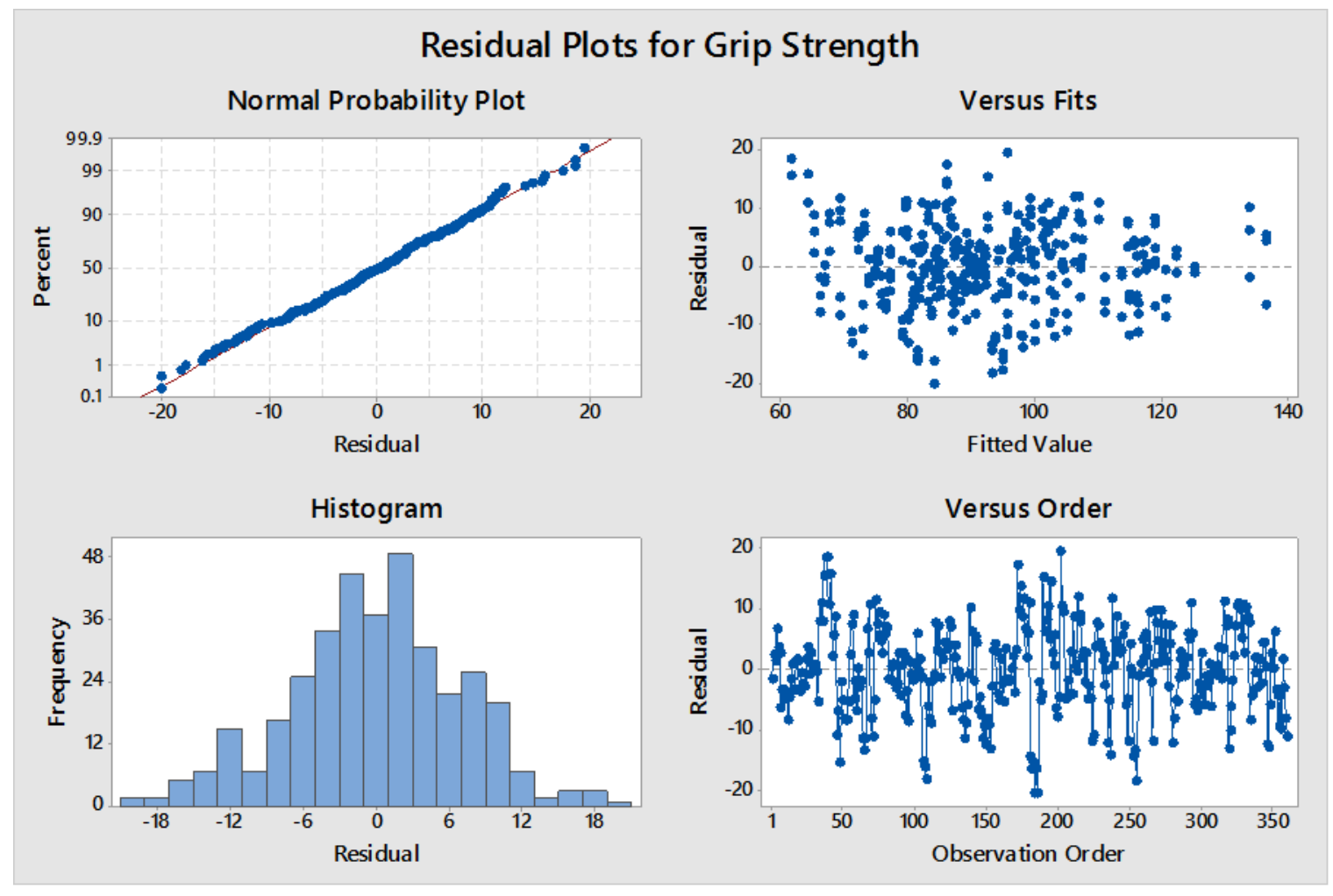

Test for Equal Variances: Grip Strength vs Glove type, Posture

Multiple comparison intervals for the standard deviation, $\alpha=0.05$

Glove type Posture

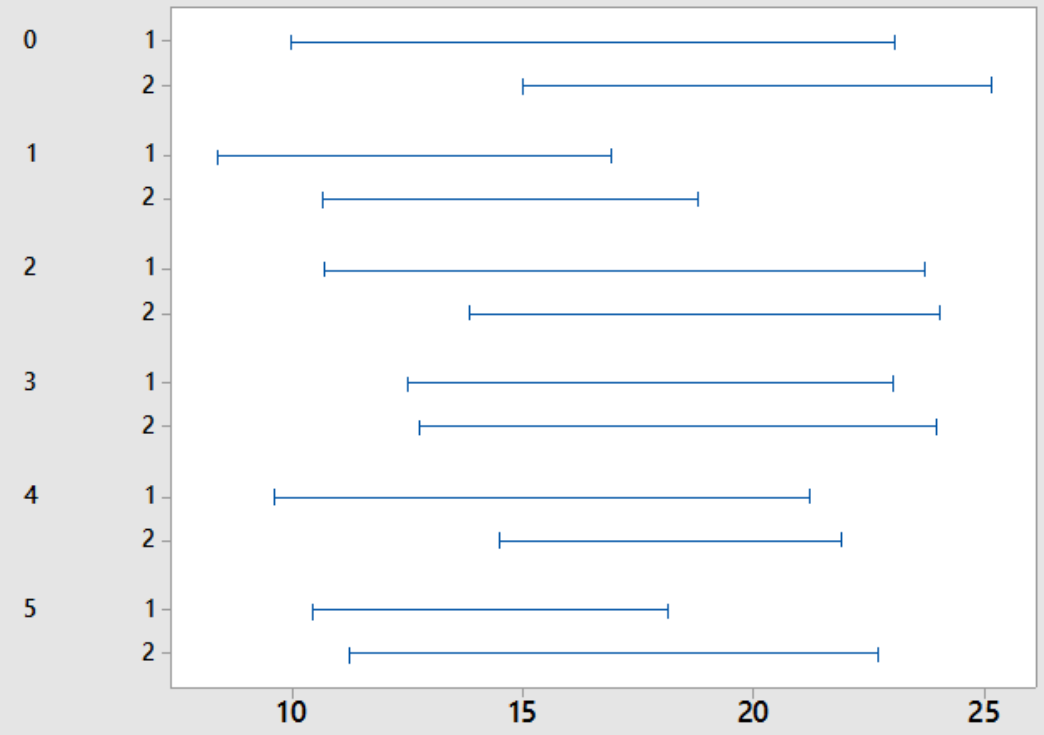

Multiple Comparisons P-Value 0.262 Levene's Test

P-Value 0.463

If intervals do not overlap, the corresponding stdevs are significantly different. 


\section{Test for Equal Variances: Pinch Strength vs Glove type, Posture}

Multiple comparison intervals for the standard deviation, $\alpha=0.05$

Glove type Posture

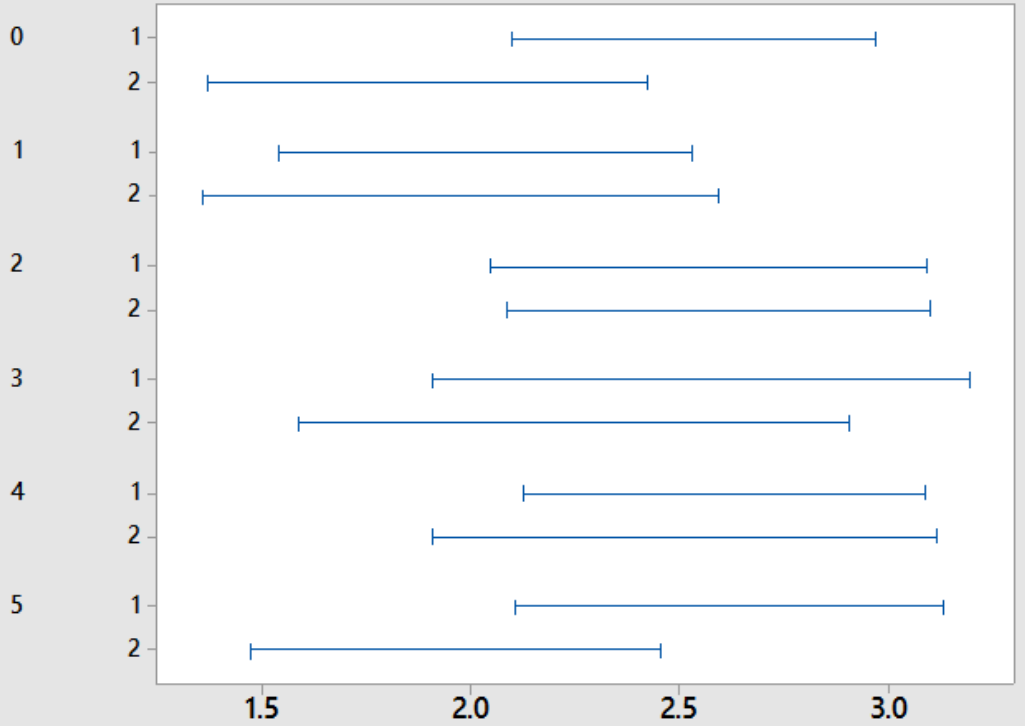

Multiple Comparisons P-Value 0.436 Levene's Test P-Value 0.036

If intervals do not overlap, the corresponding stdevs are significantly different.

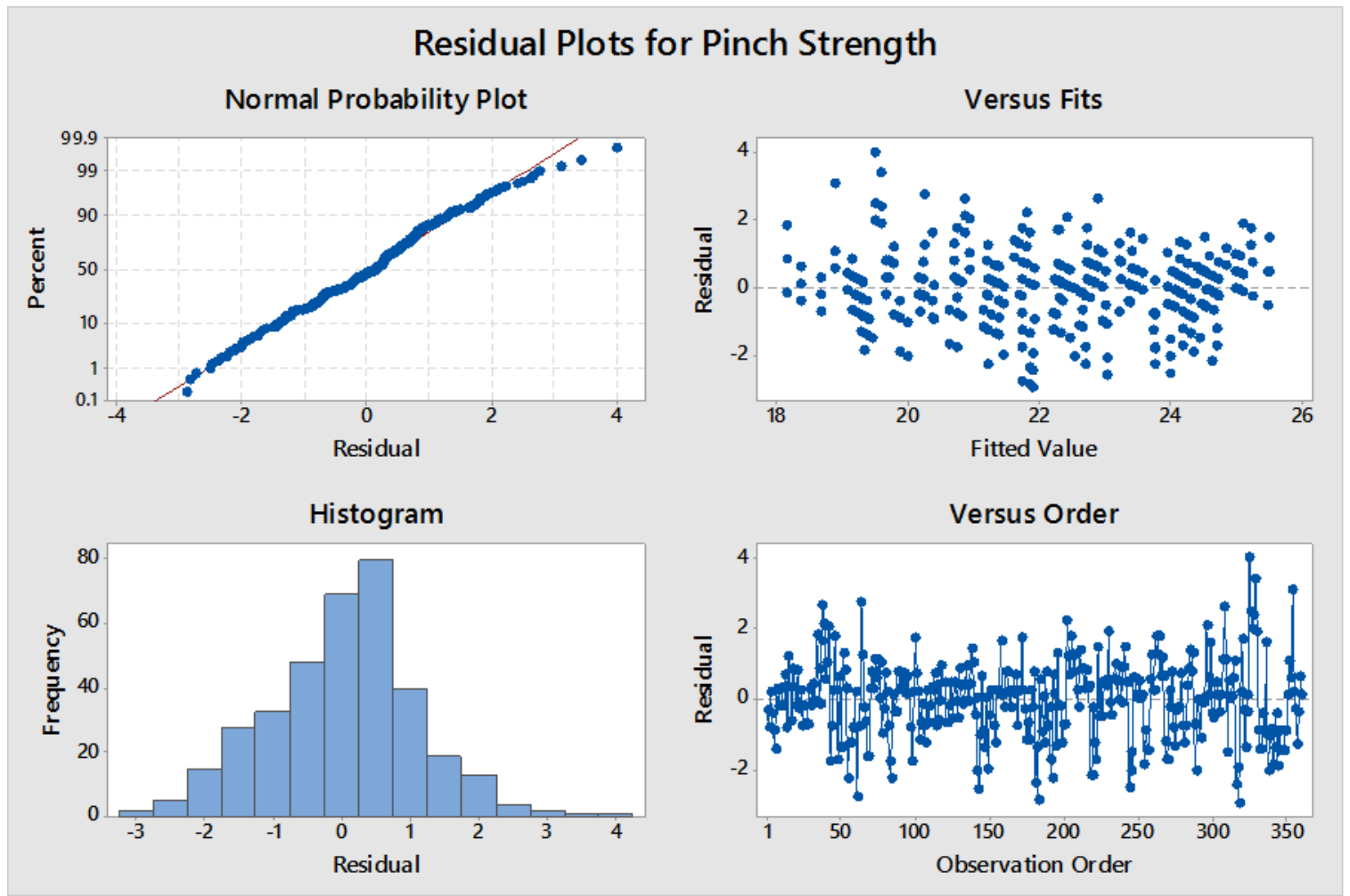




\title{
Appendix 2: Consent Form
}

\author{
Only Minimal Risk \\ Consent Information Form (without HIPAA)
}

Principal Investigator

Department

Protocol Number

Study Title

Co-Investigator(s)
Ashish Nimbarte PhD

Industrial and Management Systems

1810332591

Effect of metacarpal gloves on pinch and grip strength.

\section{Contact Persons}

In the event you experience any side effects or injury related to this research, you should contact Dr. Ashish Nimbarte at (304)-293-9473. (After hours contact: Dr. Nimbarte at (304) 226-8813. If you have any questions, concerns, or complaints about this research, you can contact Dr. Nimbarte or Aaron Fonner at (304) 639-8643.

For information regarding your rights as a research subject, to discuss problems, concerns, or suggestions related to the research, to obtain information or offer input about the research, contact the Office of Research Integrity and Compliance at (304) 293-7073.

In addition if you would like to discuss problems, concerns, have suggestions related to research, or would like to offer input about the research, contact the Office of Research Integrity and Compliance at 304-293-7073.

\section{Introduction}

You, , have been asked to participate in this research study, which has been explained to you by Dr. Nimbarte or Aaron Fonner. This study is being conducted by Dr. Nimbarte and Aaron Fonner in the Department of Industrial and Systems Management at West Virginia University.

\section{Purpose(s) of the Study}

The purpose of this study if to determine whether protective metacarpal gloves restrict the ability to apply force when performing pinching and gripping tasks.

\section{Description of Procedures}

A laboratory-based study will be conducted to determine exactly how much a thick, protective metacarpal glove will negatively affect workers' hand performance. Participants will perform maximum forceful exertions of key pinch grip 
10 male participants will be recruited to undergo this study. A Jamar pinch meter and Jamar hydraulic hand dynamometer (JLW Instruments., Chicago IL) will be used to measure the maximum strengths. The strengths will be measured using 2 different postures. The first posture is standing, and it is where the shoulder is adducted and neutrally rotated and elbow in full extension (elbow at 90 degrees). The second posture is also standing, the arm will be in full abduction with the bicep muscle close to the participant's ear as close to 180 degrees as possible. Six glove conditions will be tested - no glove and five metacarpal gloves. Each experimental condition will be repeated at least 3 times. Thus, an individual participant will perform 72 experimental trials, 2 types of force exertions (pinch and grip) $\times 2$ postures $\times 6$ glove conditions $x 3$ repetitions. Each maximum strength measurement trial will involve applying the force slowly and steadily without a jerking motion, until maximum force is reached. 3 trials of maximum strength measurement will be collected. In the cases where variability was $>10 \%$ between trails, a 4 th trial will be performed and the average of the best 3 values will be used to determine pinch/gripping

\section{Discomforts}

There are no known or expected risks from participating in this study.

\section{Alternatives}

You do not have to participate in this study.

\section{Benefits}

You may not receive any direct benefit from this study. The knowledge gained from this study may eventually benefit others.

\section{Financial Considerations}

There are no special fees for participating in this study.

\section{Confidentiality}

Any information about you that is obtained as a result of your participation in this research will be kept as confidential as legally possible. Your research records and test results, just like hospital records, may be subpoenaed by court order or may be inspected by the study sponsor or federal regulatory authorities without your additional consent.

\section{Voluntary Participation}

Participation in this study is voluntary. You are free to withdraw your consent to participate in this study at any time.

Refusal to participate or withdrawal will not affect and will involve no penalty to you.

In the event new information becomes available that may affect your willingness to participate in this study, this information will be given to you so that you can make an informed decision about whether or not to continue your participation. 
You have been given the opportunity to ask questions about the research, and you have received answers concerning areas you did not understand.

Upon signing this form, you will receive a copy.

I willingly consent to participate in this research.

\section{Signatures}

Signature of Subject

Printed Name

Date

Time

The participant has had the opportunity to have questions addressed. The participant willingly agrees to be in the study.

Signature of Investigator or Co-Investigator

Printed Name

Date

Time 


\section{Appendix 3: Raw Data}

\begin{tabular}{|c|c|c|c|}
\hline Ryan & Trial 1 & Trial 2 & Trial 3 \\
\hline Po2HDG5 & 97 & 95 & 95 \\
\hline Po1HDG3 & 84.5 & 87.5 & 90 \\
\hline Po2HDG4 & 96.5 & 96 & 96 \\
\hline Po2HDG2 & 91 & 92 & 87.5 \\
\hline Po1PG5 & 20 & 19.5 & 19.5 \\
\hline Po1HDG5 & 91.5 & 93.5 & 89 \\
\hline Po2PG2 & 20.5 & 20 & 20 \\
\hline Po1PG3 & 20.5 & 19 & 21 \\
\hline Po1PNG & 19.5 & 19 & 19 \\
\hline Po1PG4 & 20 & 19.5 & 20.5 \\
\hline Po2HDG3 & 89 & 89 & 94 \\
\hline Po2HDNG & 118 & 112 & 118 \\
\hline Po1PG2 & 19.5 & 19 & 19.5 \\
\hline Po2PG4 & 19 & 19.5 & 18.5 \\
\hline Po2PG3 & 19.5 & 18.5 & 20 \\
\hline Po1HDNG & 108 & 107 & 102 \\
\hline Po1HDG2 & 82 & 85 & 85 \\
\hline Po2PNG & 20 & 19 & 18 \\
\hline Po1HDG4 & 92 & 87 & 90 \\
\hline Po1HDG1 & 83 & 87 & 86 \\
\hline Po2HDG1 & 94 & 91 & 90 \\
\hline Po2PG1 & 90 & 85.5 & 88 \\
\hline Po1PG1 & 19 & 18.5 & 19.5 \\
\hline Po2PG5 & 18 & 19 & 18.5 \\
\hline Brandon & Trial 1 & Trial 2 & Trial 3 \\
\hline Po2HDG5 & 60 & 58 & 60 \\
\hline Po1HDG3 & 64 & 61 & 58 \\
\hline Po2HDG4 & 71 & 74 & 69 \\
\hline Po2HDG2 & 62 & 66 & 57.5 \\
\hline Po1PG5 & 19 & 21 & 21 \\
\hline Po1HDG5 & 67 & 64 & 65 \\
\hline Po2PG2 & 23.5 & 22 & 20 \\
\hline Po1PG3 & 22 & 20 & 20 \\
\hline
\end{tabular}




$\begin{array}{lrrrl}\text { Po1PNG } & 20 & 19 & 19 & \mathrm{lbs} \\ \text { Po1PG4 } & 19 & 20 & 20 & \mathrm{lbs} \\ \text { Po2HDG3 } & 61 & 61 & 64 & \mathrm{lbs} \\ \text { Po2HDNG } & 79 & 76 & 82 & \mathrm{lbs} \\ \text { Po1PG2 } & 19 & 20 & 21 & \mathrm{lbs} \\ \text { Po2PG4 } & 20 & 20 & 21 & \mathrm{lbs} \\ \text { Po2PG3 } & 22 & 21.5 & 21 & \mathrm{lbs} \\ \text { Po1HDNG } & 91 & 87 & 95 & \mathrm{lbs} \\ \text { Po1HDG2 } & 67.5 & 71 & 74 & \mathrm{lbs} \\ \text { Po2PNG } & 20 & 20.5 & 20 & \mathrm{lbs} \\ \text { Po1HDG4 } & 70 & 75 & 76.5 & \mathrm{lbs} \\ \text { Po1HDG1 } & 77 & 80 & 80 & \mathrm{lbs} \\ \text { Po2HDG1 } & 75 & 75 & 80 & \mathrm{lbs} \\ \text { Po2PG1 } & 21.5 & 22 & 23 & \mathrm{lbs} \\ \text { PoPG1 } & 22.5 & 23.5 & 23 & \mathrm{lbs} \\ \text { Po2PG5 } & 23 & 21.5 & 20 & \mathrm{lbs} \\ & & & & \\ \text { Rj } & \text { Trial } 1 & \text { Trial } 2 & \text { Trial } 3 & \mathrm{lbs} \\ \text { Po2HDG5 } & 80 & 80 & 85 & \mathrm{lbs} \\ \text { Po1HDG3 } & 75 & 72 & 71 & \mathrm{lbs} \\ \text { Po2HDG4 } & 76 & 80 & 75 & \mathrm{lbs} \\ \text { Po2HDG2 } & 79 & 79 & 81 & \mathrm{lbs} \\ \text { Po1PG5 } & 23 & 22 & 24 & \mathrm{lbs} \\ \text { Po1HDG5 } & 76 & 74 & 73 & \mathrm{lbs} \\ \text { Po2PG2 } & 23 & 22 & 21.5 & \mathrm{lbs} \\ \text { Po1PG3 } & 23.5 & 23 & 23 & \mathrm{lbs} \\ \text { Po1PNG } & 21.5 & 22 & 22.5 & \mathrm{lbs} \\ \text { Po1PG4 } & 24 & 23.5 & 24 & \mathrm{lbs} \\ \text { Po2HDG3 } & 75 & 80 & 73 & \mathrm{lbs} \\ \text { Po2HDNG } & 80 & 79 & 77 & \mathrm{lbs} \\ \text { Po1PG2 } & 22.5 & 23.5 & 23 & \mathrm{lbs} \\ \text { Po2PG4 } & 23 & 23.5 & 23 & \mathrm{lbs} \\ \text { Po2PG3 } & 23.5 & 23.5 & 23 & \mathrm{lbs} \\ \text { Po1HDNG } & 92 & 94 & 91 & \mathrm{lbs} \\ \text { Po1HDG2 } & 82 & 79 & 80 & \mathrm{lbs} \\ \text { Po2PNG } & 21 & 20.5 & 22 & \mathrm{lbs} \\ \text { Po1HDG4 } & 76 & 78 & 77.5 & \mathrm{lbs} \\ \text { Po1HDG1 } & 81 & 77 & 79 & \mathrm{lbs} \\ & & & & \end{array}$




$\begin{array}{llrrl}\text { Po2HDG1 } & 78 & 77 & 75 & \text { lbs } \\ \text { Po2PG1 } & 23 & 24 & 22 & \text { lbs } \\ \text { Po1PG1 } & 24 & 23.5 & 24 & \text { lbs } \\ \text { Po2PG5 } & 24 & 23 & 22.5 & \text { lbs }\end{array}$

Jake $\quad$ Trial 1 Trial 2 Trial $3 \quad$ Ibs

\begin{tabular}{|c|c|c|c|c|}
\hline Po2HDG5 & 112 & 115 & 120 & \\
\hline Po1HDG3 & 120 & 120 & 119 & \\
\hline Po2HDG4 & 125 & 125 & 124 & \\
\hline Po2HDG2 & 121 & 125 & 124 & \\
\hline Po1PG5 & 25 & 25.5 & 26 & \\
\hline Po1HDG5 & 110 & 108 & 105 & \\
\hline Po2PG2 & 26 & 25.5 & 25.5 & \\
\hline Po1PG3 & 24 & 24 & 24.5 & \\
\hline Po1PNG & 25 & 23.5 & 24 & \\
\hline Po1PG4 & 25 & 24.5 & 24 & \\
\hline Po2HDG3 & 127 & 126 & 112 & \\
\hline Po2HDNG & 136 & 143 & 142.5 & \\
\hline Po1PG2 & 23.5 & 24.5 & 24 & \\
\hline Po2PG4 & 25 & 24.5 & 24 & \\
\hline Po2PG3 & 24.5 & 23.5 & 24.5 & \\
\hline Po1HDNG & 144 & 140 & 132 & \\
\hline Po1HDG2 & 122.5 & 118 & 132 & \\
\hline Po2PNG & 142 & 141 & 130 & \\
\hline Po1HDG4 & 119 & 121 & 119 & \\
\hline Po1HDG1 & 105 & 109 & 103 & \\
\hline Po2HDG1 & 105 & 112 & 113 & \\
\hline Po2PG1 & 24.5 & 25 & 23.5 & \\
\hline Po1PG1 & 23.5 & 24 & 24.5 & \\
\hline Po2PG5 & 23.5 & 24 & 25 & \\
\hline Byan & Trial 1 & Trial 2 & Trial 3 & Trial 4 \\
\hline Po2HDG5 & 103.5 & 96 & 100 & \\
\hline
\end{tabular}




\begin{tabular}{|c|c|c|c|c|}
\hline Po1HDG3 & 84 & 77 & 76 & \\
\hline Po2HDG4 & 89 & 89 & 91 & \\
\hline Po2HDG2 & 85 & 91 & 92 & \\
\hline Po1PG5 & 21.5 & 22.5 & 22.5 & \\
\hline Po1HDG5 & 84 & 78 & 85 & \\
\hline Po2PG2 & 21 & 22.5 & 22.5 & \\
\hline Po1PG3 & 22 & 23.5 & 22 & \\
\hline Po1PNG & 20 & 20.5 & 20 & \\
\hline Po1PG4 & 22 & 21.5 & 22 & \\
\hline Po2HDG3 & 86 & 82 & 79 & \\
\hline Po2HDNG & 104 & 108 & 113 & \\
\hline Po1PG2 & 21.5 & 21.5 & 20.5 & \\
\hline Po2PG4 & 21.5 & 22 & 22 & \\
\hline Po2PG3 & 21 & 22 & 22 & \\
\hline Po1HDNG & 108 & 111 & 106 & \\
\hline Po1HDG2 & 72 & 71 & 67 & \\
\hline Po2PNG & 20.5 & 20 & 21 & \\
\hline Po1HDG4 & 86 & 81 & 81 & \\
\hline Po1HDG1 & 70 & 72 & 69 & \\
\hline Po2HDG1 & 68 & 70 & 67 & \\
\hline Po2PG1 & 21.5 & 19.5 & 21 & \\
\hline Po1PG1 & 22 & 20.5 & 20 & \\
\hline Po2PG5 & 22.5 & 21 & 20.5 & \\
\hline Michael & Trial 1 & Trial 2 & Trial 3 & Trial 4 \\
\hline Po2HDG5 & 87 & 94 & 87 & \\
\hline Po1HDG3 & 96.5 & 91 & 100.5 & \\
\hline Po2HDG4 & 115 & 106 & 105 & \\
\hline Po2HDG2 & 108 & 99 & 101 & \\
\hline Po1PG5 & 24.5 & 24 & 23.5 & \\
\hline Po1HDG5 & 82 & 82 & 85 & \\
\hline Po2PG2 & 22.5 & 21 & 20.5 & \\
\hline Po1PG3 & 23 & 22.5 & 21 & \\
\hline Po1PNG & 23 & 22.5 & 22.5 & \\
\hline Po1PG4 & 21 & 21.5 & 21.5 & \\
\hline Po2HDG3 & 92 & 90 & 95 & \\
\hline Po2HDNG & 119 & 116 & 115 & \\
\hline Po1PG2 & 20.5 & 22.5 & 21 & \\
\hline
\end{tabular}




\begin{tabular}{|c|c|c|c|c|c|}
\hline Po2PG4 & 24 & 23 & 22.5 & & Ibs \\
\hline Po2PG3 & 23 & 21.5 & 21.5 & & lbs \\
\hline Po1HDNG & 113 & 105 & 104 & & \\
\hline Po1HDG2 & 83 & 80 & 81 & & \\
\hline Po2PNG & 21 & 21.5 & 21 & & \\
\hline Po1HDG4 & 81 & 79.5 & 83 & & \\
\hline Po1HDG1 & 67 & 55 & 66 & 52.5 & \\
\hline Po2HDG1 & 64 & 68 & 64 & & \\
\hline Po2PG1 & 22.5 & 21 & 22 & & \\
\hline Po1PG1 & 19.5 & 20.5 & 19 & & \\
\hline Po2PG5 & 22.5 & 21.5 & 21 & & \\
\hline Josh M & Trial 1 & Trial 2 & Trial 3 & Trial 4 & \\
\hline Po2HDG5 & 105 & 107.5 & 109 & & \\
\hline Po1HDG3 & 101 & 100 & 98 & & \\
\hline Po2HDG4 & 118 & 107 & 111 & & \\
\hline Po2HDG2 & 107 & 111 & 110.5 & & \\
\hline Po1PG5 & 27 & 26 & 26 & & \\
\hline Po1HDG5 & 106 & 101 & 100 & & \\
\hline Po2PG2 & 25 & 26 & 26 & & \\
\hline Po1PG3 & 25.5 & 27 & 25 & & \\
\hline Po1PNG & 25 & 25 & 24.5 & & \\
\hline Po1PG4 & 26 & 21.5 & 25 & 24 & \\
\hline Po2HDG3 & 97.5 & 102.5 & 100 & & \\
\hline Po2HDNG & 122 & 118 & 117 & & \\
\hline Po1PG2 & 26 & 24 & 25 & & \\
\hline Po2PG4 & 25.5 & 24.5 & 25.5 & & \\
\hline Po2PG3 & 24 & 25 & 25 & & \\
\hline Po1HDNG & 109 & 110 & 103 & & \\
\hline Po1HDG2 & 91 & 74 & 85 & 87 & \\
\hline Po2PNG & 23.5 & 24 & 23.5 & & \\
\hline Po1HDG4 & 86 & 93 & 84 & & \\
\hline Po1HDG1 & 94 & 95 & 90 & & \\
\hline Po2HDG1 & 97.5 & 90 & 92 & & \\
\hline Po2PG1 & 24.5 & 23.5 & 23 & & \\
\hline Po1PG1 & 25 & 22.5 & 22.5 & & \\
\hline Po2PG5 & 21.5 & 22.5 & 22 & & \\
\hline
\end{tabular}




\begin{tabular}{|c|c|c|c|c|}
\hline Kyle & Trial 1 & Trial 2 & Trial 3 & Trial 4 \\
\hline Po2HDG5 & 91 & 95 & 98 & \\
\hline Po1HDG3 & 96 & 86 & 99 & \\
\hline Po2HDG4 & 112 & 115 & 109 & \\
\hline Po2HDG2 & 108 & 104 & 114 & \\
\hline Po1PG5 & 25 & 25 & 26 & \\
\hline Po1HDG5 & 96 & 103 & 106 & \\
\hline Po2PG2 & 27 & 26.5 & 27 & \\
\hline Po1PG3 & 25.5 & 26 & 25.5 & \\
\hline Po1PNG & 24.5 & 25 & 25.5 & \\
\hline Po1PG4 & 25 & 24.5 & 25.5 & \\
\hline Po2HDG3 & 111 & 109 & 106 & \\
\hline Po2HDNG & 122 & 119 & 120 & \\
\hline Po1PG2 & 25.5 & 24.5 & 24.5 & \\
\hline Po2PG4 & 23.5 & 23 & 24 & \\
\hline Po2PG3 & 23 & 22.5 & 22.5 & \\
\hline Po1HDNG & 111 & 115 & 118 & \\
\hline Po1HDG2 & 102 & 99 & 103 & \\
\hline Po2PNG & 24 & 24.5 & 22.5 & \\
\hline Po1HDG4 & 100.5 & 109 & 102 & \\
\hline Po1HDG1 & 79 & 80 & 75 & \\
\hline Po2HDG1 & 95 & 95 & 97 & \\
\hline Po2PG1 & 23 & 23 & 25 & \\
\hline Po1PG1 & 24.5 & 22.5 & 23.5 & \\
\hline Po2PG5 & 23 & 22.5 & 23 & \\
\hline Josh D & Trial 1 & Trial 2 & Trial 3 & Trial 4 \\
\hline Po2HDG5 & 98 & 94 & 95 & \\
\hline Po1HDG3 & 76 & 79 & 76 & \\
\hline Po2HDG4 & 90.5 & 92 & 95 & \\
\hline Po2HDG2 & 86 & 85 & 91 & \\
\hline Po1PG5 & 23.5 & 24 & 24.5 & \\
\hline Po1HDG5 & 82 & 81 & 86 & \\
\hline Po2PG2 & 23.5 & 25 & 23 & \\
\hline Po1PG3 & 22.5 & 18 & 23.5 & 22.0 \\
\hline Po1PNG & 22.5 & 24 & 22 & \\
\hline Po1PG4 & 24 & 25.5 & 24 & \\
\hline Po2HDG3 & 84 & 83 & 86 & \\
\hline
\end{tabular}




\begin{tabular}{|c|c|c|c|c|}
\hline Po2HDNG & 101 & 105 & 110 & \\
\hline Po1PG2 & 22.5 & 24.5 & 23 & \\
\hline Po2PG4 & 21 & 23 & 22.5 & \\
\hline Po2PG3 & 22.5 & 22 & 22.5 & \\
\hline Po1HDNG & 87 & 90 & 94 & \\
\hline Po1HDG2 & 75 & 76 & 74 & \\
\hline Po2PNG & 20 & 21 & 20.5 & \\
\hline Po1HDG4 & 77 & 83.5 & 83 & \\
\hline Po1HDG1 & 76 & 79 & 83 & \\
\hline Po2HDG1 & 85 & 91 & 86 & \\
\hline Po2PG1 & 21.5 & 22.5 & 22.5 & \\
\hline Po1PG1 & 20.5 & 22.5 & 22.5 & \\
\hline Po2PG5 & 19.5 & 20 & 19 & \\
\hline Devin & Trial 1 & Trial 2 & Trial 3 & Trial 4 \\
\hline Po2HDG5 & 86 & 85 & 80 & \\
\hline Po1HDG3 & 86 & 83.5 & 86 & \\
\hline Po2HDG4 & 81.5 & 81 & 88 & \\
\hline Po2HDG2 & 82.5 & 86.5 & 87.5 & \\
\hline Po1PG5 & 19.5 & 19.5 & 20.5 & \\
\hline Po1HDG5 & 87.5 & 75 & 91 & 89.0 \\
\hline Po2PG2 & 20 & 19.5 & 22 & \\
\hline Po1PG3 & 19 & 18 & 19 & \\
\hline Po1PNG & 19.5 & 19 & 18 & \\
\hline Po1PG4 & 19.5 & 18 & 19 & \\
\hline Po2HDG3 & 84.5 & 89 & 85 & \\
\hline Po2HDNG & 102 & 97 & 94 & \\
\hline Po1PG2 & 18.5 & 18 & 18 & \\
\hline Po2PG4 & 18 & 18 & 18 & \\
\hline Po2PG3 & 18.5 & 17.5 & 18 & \\
\hline Po1HDNG & 96 & 92.5 & 104 & \\
\hline Po1HDG2 & 93.5 & 92 & 91 & \\
\hline Po2PNG & 18 & 19 & 18.5 & \\
\hline Po1HDG4 & 90 & 90 & 86 & \\
\hline Po1HDG1 & 90 & 90.5 & 89.5 & \\
\hline Po2HDG1 & 87.5 & 93 & 85 & \\
\hline Po2PG1 & 22 & 23 & 21.5 & \\
\hline Po1PG1 & 23.5 & 22 & 21.5 & \\
\hline
\end{tabular}


$\begin{array}{lllll}\text { Po2PG5 } & 23 & 22.5 & 22 & \text { lbs }\end{array}$ 